\title{
Correlation between motor function recovery and daily living activity outcomes after brachial plexus surgery
}

\author{
Correlação entre a recuperação motora funcional e as atividades de vida diária após \\ cirurgia do plexo braquial
}

Sonia Regina Ferreiraำ, Roberto Sérgio Martins ${ }^{1}$, Mário G. Siqueira ${ }^{1}$

\begin{abstract}
Objective: To establish the correlation between clinical evaluation of motor function recovery and daily living activities in 30 patients with upper traumatic brachial plexus injury submitted to surgery. Methods: The score of the Disabilities of the Arm, Shoulder and Hand (DASH) questionnaire and the Louisiana State University Health Sciences Center (LSUHSC) scale were determined in 30 patients. Epidemiologic factors were also examined and correlations were determined. Results: There was a significant correlation between the clinical evaluation and the daily living activities after a 12-month period $(r=0.479$ and $p=0.007)$. A direct correlation was observed between the functional recovery of the upper limb and the time between injury and surgery $(r=0.554$ and $p=0.001)$. The LSUHSC scores ( $p=0.049)$ and scores from the DASH questionnaire ( $p=0.013)$ were better among patients who returned to work. Conclusions: Clinical evaluation and daily living activities in adult patients who underwent nerve transfer after brachial plexus injury showed significant and measurable improvements.
\end{abstract}

Keywords: brachial plexus; nerve transfer; activities of daily living.

\section{RESUMO}

Objetivo: Avaliar a correlação entre a avaliação clínica e as atividades de vida diária em 30 paciente adultos com lesão do plexo braquial superior. Métodos: O valor do questionário Dash (Disabilities of the Arm, Shoulder and Hand) e da escala Louisiana State University Health Sciences Center (LSUHSC) foram quantificados prospectivamente em 30 pacientes. Fatores epidemiológicos foram também examinados e correlações específicas determinadas. Resultados: Houve correlação significativa entre avaliação clínica e as atividades de vida diária 12 meses após a cirurgia $(r=0.479$ e $p=0.007)$. Uma correlação direta foi observada entre a recuperação funcional do membro superior e o tempo entre a lesão e a cirurgia $(r=0.554$ e $p=0.001)$. Os valores da escala LSUHSC ( $p=0.049)$ e do DASH $(p=0.013)$ foram melhores entre aqueles que retornaram ao trabalho. Conclusões: A avaliação clínica e as atividades de vida diária em pacientes submetidos à cirurgia de transferência de nervos após lesão do plexo braquial mostraram correlação significativa.

Palavras-chave: plexo braquial; transferência de nervo; atividades cotidianas.

The brachial plexus provides motor and sensory innervation to muscles in the shoulders, arms, wrist and fingers. Traumatic injury of the brachial plexus due to upper trunk injury is common among victims of motorcycle accidents. Damage to the C5-C6 nerves cause dysfunction of shoulder joint movement, forearm flexion, forearm external rotation and wrist flexion (to a certain degree). In addition, C5-C7 nerve injuries cause a reduction in the forearm extension ${ }^{1,2}$.

Restoring active forearm flexion is the primary goal of surgical treatment of upper trunk brachial plexus injuries $^{3,4}$. This injury affects motor function and can impair the ability of patients to do physical work as well as engage in their activities of daily living. Although recent studies of nerve transfers after traumatic brachial plexus in adults have shown excellent functional outcomes, evaluations of daily living activities have not routinely been performed following this surgery ${ }^{5,6}$.

The Disabilities of the Arm, Shoulder and Hand (DASH), a 30-item self-report questionnaire ${ }^{7}$, was translated to Brazilian Portuguese and referred to as the DASH Brazil questionnaire ${ }^{8}$. It has been used to describe moderate or severe disabilities of the upper limbs in multiple disorders. Although the DASH has

1 Universidade de São Paulo, Faculdade de Medicina, Instituto de Psiquiatria, Divisão de Neurocirurgia Funcional, Unidade de Cirurgia de Nervo Periférico, São Paulo, SP, Brasil.

Correspondence: Sonia Regina Ferreira; Rua Hematita, 207; 05180-120 São Paulo SP, Brasil; E-mail: soniaregi@gmail.com

Conflict of interest: There is no conflict of interest to declare.

Received 21 March 2017; Accepted 22 May 2017. 
been the most widely-used patient-reported questionnaire for brachial plexus injury ${ }^{9}$. This tool is rarely used to describe the outcomes in adults undergoing nerve transposition surgery after traumatic brachial plexus injury ${ }^{10}$. In the DASH questionnaire, each item is ranked on a five-point scale. Its total score calculation ranges from 0 to $100^{11}$. A higher DASH score reflects a higher level of disability ${ }^{7,11}$ and a score of 10 or less is within normal limits, according to data from the USA general population norm study ${ }^{6}$.

The purpose of this paper was to correlate motor function recovery of the upper limbs as measured by the Louisiana State University Health Sciences Center (LSUHSC) scale and the ability of the patients to perform their daily living activities using the DASH Brazil questionnaire. To the best of our knowledge, there was no study in the literature that correlated the LSUHSC score and the results of the DASH Brazil questionnaire in patients with $\mathrm{C5}$-C6 or $\mathrm{C} 5-\mathrm{C} 7$ injury, who have undergone nerve transfer.

\section{METHODS}

\section{Patient population}

This study was conducted following a protocol approved by the Ethics Research Commissions on Human Research at the University of São Paulo Medical School (approval number 266.433). The recruitment began in October 2013 and finished in December 2014. The study was conducted at the Peripheral Nerve Surgery Unit at the Functional Neurosurgery Division of the Psychiatry Institute/University of São Paulo Medical School.

The primary goal of this study was to correlate the daily living activities and recovery of motor function, and the secondary goals were to correlate these outcomes with those routinely recorded after surgery, such as age, sex, dominant and non-dominant side and the ability to return to work.

We report on the results of 30 patients who met the inclusion criteria and had a postoperative follow-up for a minimum of one year. The inclusion criteria were adult patients with C5, C6 or additional C7 lesions after traumatic brachial plexus injury who underwent nerve transfer surgery and did not present with associate fractures or lesions.
A total of 23 male, and seven female patients between the ages of 22 and 68 years $(37.5 \pm 55$ years [mean \pm SD] $)$ were evaluated. The dominant extremity was affected in 12 of the 30 patients. The extent of injury at diagnosis was established by clinical evaluation, and the preoperative diagnosis was confirmed by electrophysiological evaluation and surgical exploration. The time between the traumatic brachial plexus injury and the nerve transfer surgery ranged from three to 17 months $(7.6 \pm 3.49$ months [mean $\pm \mathrm{SD}])$.

\section{Outcome assessment \\ Motor evaluation}

Evaluation of upper limb motor function was performed using the LSUHSC scale, which can be used following surgery to repair the upper injury to the brachial plexus (Table).

\section{Daily living activities}

The daily living activities were assessed independently by an occupational therapist using self-reporting and administration of the DASH Brazil questionnaire one year after surgery.

\section{Statistical analysis}

The demographic, clinical characteristics and assessments were expressed as the mean, standard deviation, median, minimum and maximum as appropriate. The Spearman's rank correlation coefficient was used to correlate the DASH Brazil questionnaire and the LSUHSC scores at a significance level of $5 \%$ or lower.

Fisher's exact test, Student's t-test and Mann-Whitney test with significance set at $5 \%(r>0$ and $p<0.05)$ or lower were used to compare the performance of patients who returned to work. The Mann-Whitney test was used to determine the differences between the dominant side, or non-dominant side, and the ability to return to work using the DASH Brazil questionnaire responses and LSUHSC scores. The ability to return to work was estimated using simple logistic regressions for each variable and reported as the odds ratio with $95 \%$ confidence intervals. Age, sex, and the average time between the accident and the surgery were examined using statistical tests and correlated with the DASH Brazil and LSUHSC scores.

Table. The Louisiana State University Health Sciences Center (LSUHSC) grading of neural function ${ }^{12}$.

\begin{tabular}{ll}
\hline Grade & Description \\
\hline 0 & No muscle contraction \\
1 (poor) & Proximal muscles contract but not against gravity \\
2 (fair) & Proximal muscles contract against gravity and distal muscles do not contract; sensory grade, if applicable, is usually $\leq 2$ \\
3 (moderate) & $\begin{array}{l}\text { Proximal muscles contract against gravity and some resistance; some distal muscles contract against gravity; sensory } \\
\text { grade, if applicable, is usually } 3\end{array}$ \\
\hline 4 (good) & All muscles contract against gravity and some resistance; sensory grade, if applicable, is 3 or 4 \\
5 (excellent) & All muscles contract against moderate resistance; sensory grade, if applicable, is 4 \\
\hline
\end{tabular}




\section{RESULTS}

\section{Correlation between the DASH Brazil questionnaire responses and Louisiana State University Health Sciences Center (LSUHSC) scores}

According to Spearman's rank-order correlation coeffcient, both methods showed a linear statistical association between the variables $(r=0.479, p=0.007)$.

\section{Correlation between patient age and DASH Brazil questionnaire responses}

The comparison between the patients' age and the DASH Brazil questionnaire scores using Spearman's rank-order correlation coefficient $(\mathrm{r}>0, \mathrm{p}<0.05)$ showed that these two variables have a linear relationship $(r=0.397, p=0.030)$.

The patients' age and LSUHSC scores were assessed using Spearman's rank-order correlation coefficient $(r>0, p<0.05)$, which showed a positive association and a weak correlation $(\mathrm{r}=0.186, \mathrm{p}=0.323)$ between these variables.

When assessed with the time elapsed between injury and surgery using Spearman's rank-order correlation coefficient, there was a strong positive correlation identified with patient age $(r=0.038, p=0.0842)$, a moderate-to-strong correlation with the DASH Brazil questionnaire responses $(r=0.107$, $p=0.574)$ and a weak correlation with the LSUHSC scores $(\mathrm{r}=0.554, \mathrm{p}=0.001)$.

Twenty-eight patients were right handed (93.3\%) and two were left handed (6.7\%). A C5, C6 and C5-C7 nerve transfer was performed on the right arm of $12(40 \%)$ patients and on the left arm of the remaining $18(60 \%)$ patients. Regarding dominance, 18 (60\%) underwent surgery on their non-dominant arm and 12 (40\%) on their dominant arm.

According to the Mann-Whitney test ( $p>0.05$ ), injury in the dominant arm was not statistically associated with either the DASH Brazil questionnaire outcomes $(p=0.632)$ or the LSUHSC scores $(p=0.491)$. On the other hand, adults who underwent post traumatic brachial plexus injury involving C5-C6 or C5-C7 roots might experience an increased likelihood of returning to work after nerve transfer.

\section{DISCUSSION}

We have reported the results of 30 patients who underwent nerve transfer after traumatic brachial plexus injury involving $\mathrm{C} 5-\mathrm{C} 6$ or $\mathrm{C} 5-\mathrm{C} 7$ nerve roots, which results in functional deficits.

Previous studies have described severe and devastating conditions due to this injury ${ }^{12,13,14}$. However, the daily living activities in adult patients suffering from traumatic brachial plexus injury who undergo nerve transfer have not been widely reported. In 2011, Hill et al. ${ }^{15}$ reviewed 265 papers and noted the infrequent evaluation of daily living activities after brachial plexus injury. In 2015, Dy et al. ${ }^{5}$ systematically reviewed 88 papers, 83 (94\%) of which reported postoperative motor function. Of these, only five studies $(6 \%)$ reported either function or disability after nerve transfer.

The original DASH questionnaire was translated into Brazilian Portuguese, culturally adapted and validated; this modified version is known as the DASH Brazil questionnaire. The DASH Brazil questionnaire can be effectively used in research studies to screen for symptoms as well as the physical, social and psychological status of patients suffering from upper limb injury8.

The symptoms covered by the DASH questionnaire are pain, weakness and tingling/numbness. Variables that assess the physical functional status are daily activities, leisure activities, self-care, dressing, eating, sexual activities, sleep and sport/arts (optional); social status variables include family care, occupational, socializing with friends/relatives; and psychological status includes the self-image ${ }^{8}$. Novak et al. ${ }^{16}$ used the DASH for assessing symptoms in individuals after brachial plexus nerve injury with good results.

The characteristics of this study and the cause of injury fully corroborated earlier literature. Most of the patients' injuries occurred from motorcycle accidents involving young male motorcyclists on the road ${ }^{1,17}$.

In this study, the preoperative time intervals were widely varied (ranging from three to 17 months). According to previous publications, the timing of the surgery depends on the mechanism and type of injury. However, spontaneous recovery for a period of up to three months has been observed in the year after injury ${ }^{4}$.

The time elapsed between injury and surgery is one of the primary influences on the prognosis of patients who underwent brachial plexus surgery. In the present study, the average time between injury and surgery was $8.2 \pm 3.7$ months (mean \pm standard deviation), with a median of 7.5 months (range, 3.9 to 17 months).

The LSUHSC score is directly correlated with the time elapsed between injury and surgery $(r=0.554$ and $p=0.001)$, and these results were in accordance with most studies published on this subject ${ }^{4,18}$. A similar correlation, albeit weaker, was observed between the time elapsed before surgery and the DASH Brazil questionnaire responses.

In studies that evaluate how daily activities are affected by upper limb injury, the DASH questionnaire has been extensively used. However, when assessing the impact of brachial plexus injury on daily activities, the DASH questionnaire has not been widely used in patients with partial injuries ${ }^{10,18,19}$.

According to Spearman's rank-order correlation coefficient $(r>0, p<0.05)$, the DASH Brazil score showed a statistically significant linear association with the LSUHSC score $(r=0.479, p=0.007)$, age $(r=0.397, p=0.030)$ and the time between injury and surgery. This finding is consistent with the established literature. The DASH scores also showed influence regarding gender, age and the patients' 
ability to perform daily living activities after upper limb injury. In 2002, the American Academy of Orthopedic Surgeons conducted a survey among individuals in the USA $(\mathrm{n}=1800)$ and described similar correlations ${ }^{14}$.

Assessing the motor function gradation using the LSUHSC scale has been successfully applied in postoperative patients following surgery to repair traumatic brachial plexus injury ${ }^{18}$. In this study, the LSUHSC scale showed a positive correlation with the time between injury and surgery and the DASH Brazil questionnaire responses.
In conclusion, the recovery of motor function in the upper limb after nerve transfer correlated with the patients' ability to perform daily living activities. In addition, the time between injury and surgery also correlated with the recovery of upper limb function. On the other hand, side dominance and the injured arm was not was statistically associated with the LSUHSC scores and DASH Brazil questionnaire responses. Better outcomes regarding the LSUHSC scores and the DASH Brazil questionnaire responses were reported from patients who returned to work than from patients who were either retired or pensioners.

\section{References}

1. Bertelli JA, Ghizoni MF. Results and current approach for Brachial Plexus reconstruction. J Brachial Plex Peripher Nerve Inj. 2011;6(1):2.

2. Bertelli JA, Ghizoni MF. Clinical findings in C5-C6 and C5-C7 root palsies with brachial plexus traction lesions. J Hand Surg Eur. 2013;38(3):237-41. https://doi.org/10.1177/1753193412471009

3. Franchignoni F, Giordano A, Sartorio F, Vercelli S, Pascariello B, Ferriero G. Suggestions for refinement of the Disabilities of the Arm, Shoulder and Hand Outcome Measure (DASH): a factor analysis and Rasch validation study. Arch Phys Med Rehabil. 2010;91(9):1370-7. https://doi.org/10.1016/j.apmr.2010.06.022

4. Siqueira MG, Martins RS. Surgical treatment of adult traumatic brachial plexus injuries: an overview. Arq Neuropsiquiatr. 2011;69(3):528-35. https://doi.org/10.1590/S0004-282X2011000400023

5. Dy CJ, Garg R, Lee SK, Tow P, Mancuso CA, Wolfe SW. A systematic review of outcomes reporting for brachial plexus reconstruction. J Hand Surg (Am). 2015;40(2):308-13. https://doi.org/10.1016/j.jhsa.2014.10.033

6. Hunsaker FG, Cioffi DA, Amadio PC, Wright JG, Caughlin B. The American Academy of Orthopaedic Surgeons outcomes instruments: normative values from the general population. J Bone Joint Surg (Am). 2002;84-A(2):208-15. https://doi.org/10.2106/00004623-200202000-00007

7. The Institute for Work \& Health.The Dash and Quick Dash e-bulletin fall, 2012 [acess 2017 Mar 03]. Available at: http:/www.dash.iwh. on.ca/sites/dash/files/dash_e-bulletin_2012_winter

8. Orfale AG, Araújo PM, Ferraz MB, Natour J. Translation into Brazilian Portuguese, cultural adaptation and evaluation of the reliability of the Disabilities of the Arm, Shoulder and Hand questionnaire. Braz J Med Biol Res. 2005;38(2):293-302. https://doi.org/10.1590/S0100-879X2005000200018

9. Mancuso CA, Lee SK, Dy CJ, Landers ZA, Model Z, Wolfe SW. Compensation by the uninjured arm after brachial plexus injury. Hand (NY). 2016;11(4):410-5. https://doi.org/10.1177/1558944715627635
10. Ahmed-Labib M, Golan JD, Jacques L. Functional outcome of brachial plexus reconstruction after trauma. Neurosurgery. 2007;61(5):1016-22. https://doi.org/10.1227/01.neu.0000303197.87672.31

11. Novak CB, Anastakis DJ, Beaton DE, Mackinnon SE, Katz J. Validity of the Patient Specific Functional Scale in patients following upper extremity nerve injury. Hand (NY). 2013;8(2):132-8. https://doi.org/10.1007/s11552-013-9506-9

12. Kline DG. Surgical repair of brachial plexus injury.J Neurosurg. 2004;101(3):361-3. https://doi.org/10.3171/jns.2004.101.3.0361

13. Faglioni W Jr, Siqueira MG, Martins RS, Heise CO, Foroni L. The epidemiology of adult traumatic brachial plexus lesions in a large metropolis. Acta Neurochir (Wien). 2014;156(5):1025-8. https://doi.org/10.1007/s00701-013-1948-x

14. Hudak PL, Amadio PC, Bombardier C, Beaton D, Cole D, Davis A et al. Development of an upper extremity outcome measure:the DASH (disabilities of the arm, shoulder and hand). The Upper Extremity Collaborative Group (UECG). Am J Ind Med. 1996;29(6):602-8. https://doi. org/10.1002/(SICI)1097-0274(199606)29:6<602::AID-AJIM4>3.0.CO;2-L

15. Hill, BE, Williams G, Bialocerkowski AE. Clinimetric evaluation of questionnaires used to Acess activitiy after traumatic brachial plexus injury in adults:a systematic review. Phys Med Rehabil. 2011;92(12):2082-9. https://doi.org/10.1016/j.apmr.2011.07.188

16. Novak CB, Anastakis DJ, Beaton DE, Mackinnon SE, Katz J. Biomedical and psychosocial factors associated with disability after peripheral nerve injury. J Bone Joint Surg Am. 2011;93(10):929-36. https://doi.org/10.2106/JBJS.J.00110

17. Flores LP. [Epidemiologic study of the traumatic brachial plexus injuries in adults]. Arq Neuropsiquiatr. 2006;64(1):88-94. Portuguese. https://doi.org/10.1590/S0004-282X2006000100018 PMID:16622560

18. Kline DG. Timing for brachial plexus injury: a personal experience. Neurosurg Clin N Am. 2009;20(1):24-6. https://doi.org/10.1016/j.nec.2008.07.030

19. Novak CB, Anastakis DJ, Beaton DE, Katz J. Patient reported outcome following peripheral nerve injury. J Hand Surg. 2009;34A(2):281-7. https://doi.org/10.1016/j.jhsa.2008.11.017 